\title{
Evaluation of Effluent Management at the Gynco Obstetric and Pediatric Hospital of DOUALA
}

\section{Séverin Mbog Mbog ${ }^{1-2 *}$, Dieudonné Bitondo ${ }^{1,2}$, Françoise Biyong ${ }^{1,2}$, Dieudonné Adiogo ${ }^{1,2}$, Innocent Ndoh Mbue ${ }^{1,2}$, Patrice Polmbaye Ngoko $^{1,2}$ and Tania Mboute Nzekou ${ }^{1,2}$}

${ }^{1}$ Department of Quality Engineering, Health, Safety and Industrial Environment, Ecole Nationale Supérieure Polytechnique De Douala, University of Douala, Douala, Cameroon

${ }^{2}$ Laboratoire Energie, Matériaux, Modélisation et Méthodes, Ecole Doctorale Des

Sciences, Fondamentales et Appliquées, Université De Douala, Douala, Cameroon

*Corresponding Author: Séverin Mbog Mbog, Department of Quality Engineering, Health, Safety and Industrial Environment, Ecole Nationale Supérieure

Polytechnique De Douala, University of Douala, Douala, Cameroon..

DOI: 10.31080/ASMS.2022.06.1123
Received: October 29, 2021

Published: December 09, 2021

(C) All rights are reserved by Séverin Mbog

Mbog., et al.

\begin{abstract}
The study on the evaluation of the effluent management of HGOPED was carried out between March and July 2021, with the aim of proposing an appropriate management method.

Methodology: To complete this evaluation, we made an inventory of the sources of associated with wastewater mapping, to highlight the non-compliance of the mode management, we carried out a diagnosis through a checklist, Ishikawa and Pareto. Then the determination of the pollutant removal rate in the laboratory followed by a questionnaire with residents.

Results: The results on the management of HGOPED effluents enabled us to highlight the non-compliance of the wastewater treatment steps and the most important causes (methods to $33.33 \%$, material at $33.33 \%$ and financial resources at $16 \%$ ). Residents also complain foul odors and the sensitivity of the receiving environment has shown us that diseases, the most recurrent water problems, are malaria at $37.6 \% ; 24.8 \%$ typhoid; $12.8 \%$ of amoeba and scabies. All this is due to the lack of potable water. The result of laboratory analyzes revealed apart from SS (intermediate $23 \mathrm{mg} / \mathrm{l}$, downstream 30mg/l) and intermediate COD (368 mg/l) i.e., $20 \mathrm{mg} / \mathrm{l}$, $250 \mathrm{mg} / \mathrm{l}$ respectively. which were high due to the excessive presence of chemicals in the water. The slaughter rate of all physical and chemical parameters met MINEPDED discharge standards. The initial environmental analysis enabled us to highlight the significant environmental aspects that arise, among other things, from the activities carried out in the anatomy-pathology department.
\end{abstract}

Keywords: Impact; Pollutant; Management; Environment; Hgoped

\section{Introduction}

Pollution can be understood as contamination of air, water or soil (by chemical, organic or radioactive substances) altering human health, quality of life or the natural functioning of ecosystems, Serander [18]. It is also the discharge into the air, water and soil of substances that cause the degradation of living environments. When it is induced by industry, it is called industrial pollution. Sometimes, by extension, the simple very unpleasant nature of a nuisance a priori safe (ex-repeated noises) can be enough to invoke the qualifier of pollution where the word «nuisance» is usually pre- 
ferred [2]. The history of pollution accurately reflects advances in technology. Throughout the historical period and until the beginning of the industrial era, however, pollution was most limited [19]. For both industrialized and developing countries, the challenge now is to rebuild the foundations of their economies on «low carbon» strategies. They will also have to put in place policies to adapt to the effects of climate change, and the poorest countries are, in this regard, the first and hardest hit [4].

The link between the fight against poverty and the rational management of natural resources is becoming increasingly evident to many international development actors. Today, developing countries are already facing at least three major crises: the energy crisis, the food crisis and the water crisis $[10,11,23]$. Climate change exacerbates these crises and makes their solutions more complex. Added to this is the context of the economic crisis that is depleting the financial resources available for international cooperation $[4,21]$.

While the goal of sustainable development is increasingly shared today, the question of how to achieve it remains open. Corporate social responsibility (CSR) is a concept that revolves around three pillars: environmental, social, and economic [1,22]. Taking this responsibility into account is, often, promoting environmental «good practices»: managing natural resources in a sustainable and reasoned way, supporting less polluting technological innovations (energy, transport, etc.), strengthening the capacities of national institutions, supporting the definition and implementation of adaptation policies, integrating ecological dimensions into development approaches and strategies [1]. Currently, about all craft, industrial, commercial, hospital etc... Produce waste in one way or another from their farms. In Cameroon and all over the world, waste management is a thorny issue. A distinctive thorn by its typology and its dangerousness for the case of hospital waste.

Since 2012, by Decree No. 2012/2809/PM of 26 September 2012 setting the conditions for sorting, collecting, transporting, recovering, recycling, treating and final disposal of waste. Hospital waste management has been a particular concern among donors (banks) and national institutions (MINSANTE, MINEPDED). The management of Bio Medical Waste (DBM) is defined as the entire process of ensuring the hygiene of health facilities, the safety of healthcare staff and communities, from the treatment of waste from its production to its disposal $[6,21]$. Healthcare activities ge- nerate an increasing amount of hospital waste. Some waste from hospitals does not pose a particular risk and can be assimilated to household waste. Others present risks of an infectious or chemical nature $[3,20]$. Waste from hospital activities can be liquid (wastewater), solid or gaseous. «Wastewater» is water polluted by human use, consisting of any water likely to contaminate the receiving environment by chemical, physical or biological pollutants, $[6,15]$. Wastewater discharged uncontrollably into the environment can lead to several waterborne diseases that threaten human life $[7,16]$. Indeed, hospitals use many chemical substances: medicines, radioelements, disinfectants, products for care (antibiotics, solvents, heavy metals, radioelements... (Surgery,...), detergents for cleaning premises, and molecules used for medical research [5]. Which can also be loaded with microorganisms (fungi, sometimes anti-bio resistant bacteria), viruses etc. After use, these substances are found in hospital effluents, which are most often discharged in the same way as conventional urban effluents in the municipal sewerage network $[13,20]$.

\section{Problem}

studies conducted by Judicaël TODEDJI in 2020, Steve Patrick AYINI in 2019 and Alexandre REOUNODJI in 2016 have shown that poor effluent management has a weighting impact on the external environment. Despite this, the problem of liquid waste management has persisted in health facilities in Cameroon. Today, we still observe it at the gynecological obstetric and pediatric hospital in Douala. Despite the efforts of the leaders, the wastewater treatment plant of the Gynecology obstetric and pediatric hospital in Douala is still non-functional. It is in this context that we ask ourselves how does HGOPED manage its liquid waste? Hence the orientation of a theme on «HGOPED Effluent Management Assessment».

\section{Overall objective}

To evaluate HGOPED's effluent management system.

More specifically, it aims to:

- Identify the sources of effluents (wastewater) within HGOPED.

- $\quad$ Determine how effluents are managed within HGOPED.

- Analyze the impacts related to the management of effluents by HGOPED. 


\section{Material and Methodology}

\section{Identification of effluent sources}

The identification of effluent sources was done with the help of an introspection of the site and its positioning by the various buildings and services it has, then we listed the different views relating to drainage and leading to the different wastewater treatment networks. Knowing that drainage manholes are like the manholes of electrical installations, to the discrepancy on the code. At the end, we took a tour of the external environment of the gynecological obstetric and pediatric hospital of Douala, at a place called bamock, mainly at the outlet.

To have ample information on the sources of the effluents we had interviews first with the head of the hygiene and sanitation quality department and finally with the heads of the various administrative, technical and medical units. The objective of this questionnaire was to give an overview of the progress of the activities carried out by them. Subsequently to bring out three fundamental elements, namely the division of the structure into a subsystem, the identification of incoming and outgoing elements and the deduction of the sources of pollution. Using our digital camera and notepad, we collected several pieces of information.

Determination of effluent management mode: Diagnosis.

After studying the effluent management mode of HGOPED by observation, we determined the failures of it through, A compliance checklist of the different stages of wastewater treatment according to WHO. Subsequently, the Ishikawa diagram allowed us to identify the different causes of the non-compliance rates of each treatment step. And finally, the PARETO diagram: A graph representing the importance of the different causes of a phenomenon. This diagram has been used to highlight the most important causes on the total number of effects and thus to take targeted measures to improve the functioning of our system.

\section{Environmental impact analysis}

Impact analysis: An in-depth study of human-led activities to know their direct and indirect effects on the environment. To do this, we proceeded first by a semi-structured questionnaire with the surrounding population to know the sensitivity of the receiving environment, then we took two samples from the intermediate and downstream points of the waters subject to care activities. Which have been analyzed in the laboratory to determine the slaughter rate of the different physical and chemical parameters (Conductivity (cnd), hydrogen potential $(\mathrm{pH})$, temperature $(\mathrm{T})^{\circ}$, chemical oxygen demand (COD), biological oxygen demand in five days(BOD5), total nitrogen(NT), suspended solids(MES), total dissolved solids(TDS)), phosphorus (P) and chloride (CI)) characteristic of water pollution and finally an initial environmental analysis with a view to determining significant environmental aspects through the formula $\mathrm{C}=$ AES $=$ Gravity * Frequency * Sensitivity of the receiving environment * Means of control.

\section{Results}

\section{Effluent sources}

The main sources of the wastewater of the gynecological obstetric hospital of Douala come mainly from the liquids of the patients (blood, excreta, sputum, serum, gastric fluids, amniotic fluids, puncture fluids, tracheo-bronchitis aspiration...), medical products (acetic acids, lactic, citric, hydrochloric acid, sulfuric), bases (soda...), various reagents, solvents, contrasse liquids, formalin, dyes, ethyl alcohol, diluents, dialysis baths, micro mercury droplets, iodine-based solutions, etc.), and cleaning products (disinfectant, decontaminant, sterilizer, bleach, lubricant, gripper, etc.).

At the end of the interviews and observations, we found that HGOPED has at its disposal about sanitation and drainage equipment

- Washbasins in each room/department for the collection of wastewaters at the source. Some of these sinks are functional and others non-functional (Figure 1-d, b).

- The underground ducts are of compliant diameter and the manholes at a distance of a few meters from the ducts allow the verification of the flow of water.

- $\quad$ The cladding at the pre-treatment station is obstructed by coarse materials and, the covers of the settling and deicing basin are defective (Figure 1-a).

- The room reserved for biological treatment is a daycare and the devices put in place for this treatment are non-functional (Figure 1-c).

- The water pipe to the outlet is underground and the outlet is obstructed by grasses (Figure 1-e).

The wastewater collection network at the Gynecology and Pediatric Hospital of Douala is of a three-way separative type 


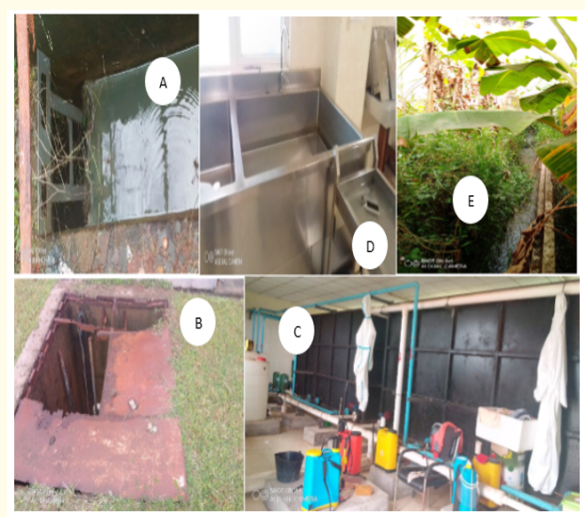

Figure 1: Inventory of sanitation equipment (A) Lid, (B) Fencing, (C) Biological treatment, (D) Washbasins.

- The wastewater route subject to care activities: this route passes not only water from care activities but also water from catering activities, laundry, and industrial maintenance.

- The rainwater route: it conducts rainwater and runoff.

- The waterway also called «black waters»: it leads the water from the latrines and the discharges to septic tanks provided for this purpose.

Next to this separative water collection network, there is an annex network located at the morgue. This network is dedicated to the management of wastewater that comes from the activities of pathology. Their evacuation is done by septic tank associated with a sump.

\section{Effluent management}

The treatment of wastewater subject to care activities begins with a degree for the retention of solids (Pre-treatment) and then the water goes through a primary treatment of physical process (simple settling). Due to the alteration of the secondary and tertiary treatment devices, the water leaves the settling phase for the outlet and is eventually discharged into the watercourse. Following our diagnosis, we can say that secondary and tertiary treatments have $0 \%$ compliance followed by pre-treatment at $33.33 \%$ and at the end primary treatment at 50\% (Figure 2).

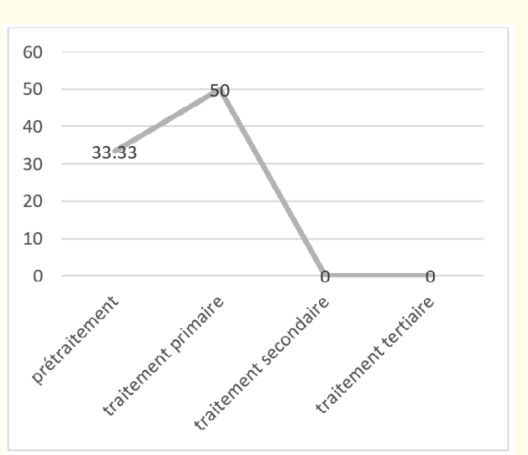

Figure 2: Management mode compliance level.

The summary of causes of non-compliance is shown in (Figure 3.)

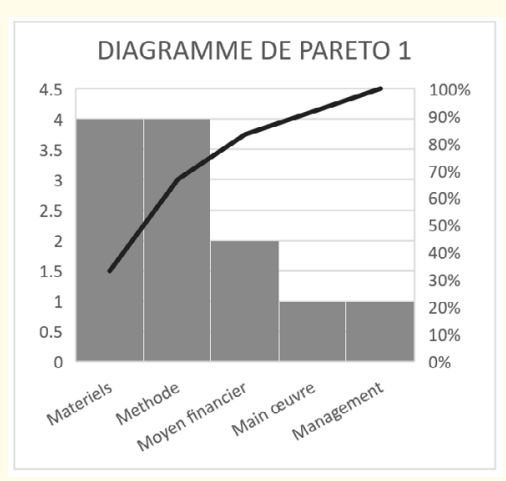

Figure 3: Diagramme de Pareto 1.

From the Pareto diagram, we can define the most important cause groups namely

- $\quad$ Class A: Equipment, method and financial means.

- Class B: Labour.

- $\quad$ Class C: Management.

Thus, the functions that carry out cash cows $(80 \%$ non-compliance) are those of methods, materials and financial means. As materials we have maintenance equipment, products (flocculant/ coagulant). Methods (sandblasting, deoiling/degreasing, flocculation/coagulation, biological treatment), and financial resources. 


\section{Environmental impact analysis}

After conducting a survey of the surrounding population, it appears that:

$54.2 \%$ of households mainly use boreholes and wells because of the lack of drinking water, $38.6 \%$ prefer drilling while $6.3 \%$ prefer wells only (Figure 4).

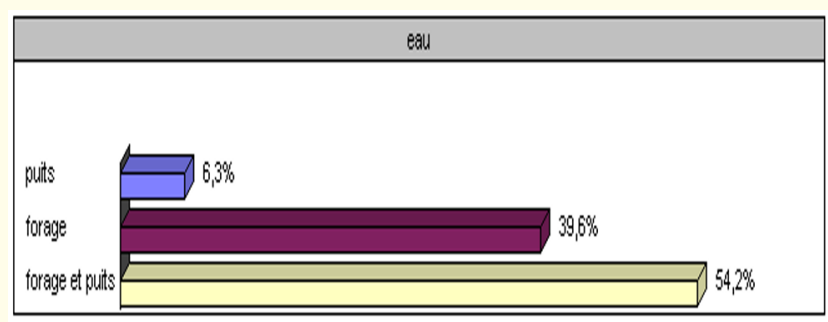

Figure 4: Source of water supply.

Most of the population only went to the hospital in case of emergency, they most often complained of malaria at 37.6\%; Typhoid at $24.8 \% ; 12.8 \%$ of amoebae. The presence of scabies is observed at $10.1 \%$ (Figure 5).

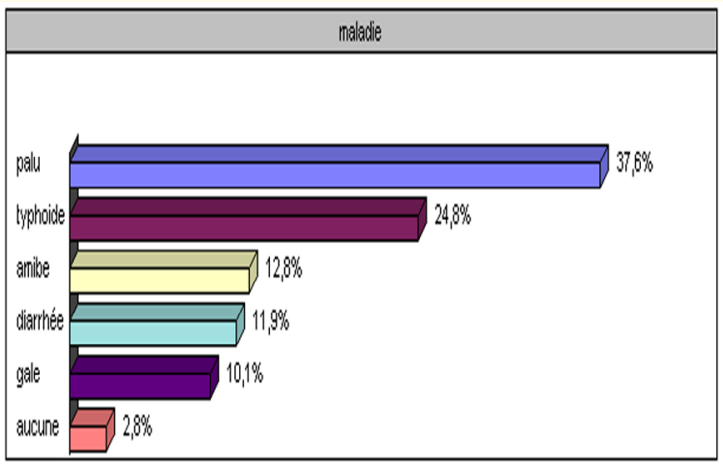

Figure 5: Waterborne diseases.

The result of the initial environmental analysis showed us that the significant environmental aspects are the chemical solutions associated with patients' germs and the various reagents used in the service of anatomy-pathology. These solutions are found in water during normal or abnormal operation. Thus, these significant environmental aspects could become insignificant if the water once polluted after use, is treated before its discharge into nature.

Laboratory analyses revealed that the Chemical Oxygen Demand of the intermediate point was $368 \mathrm{mg} / \mathrm{l}$. This value was higher than the normal impeded value of $250 \mathrm{mg} / \mathrm{l}$. This is because of the excessive presence of chemicals in the water (Figure 6).

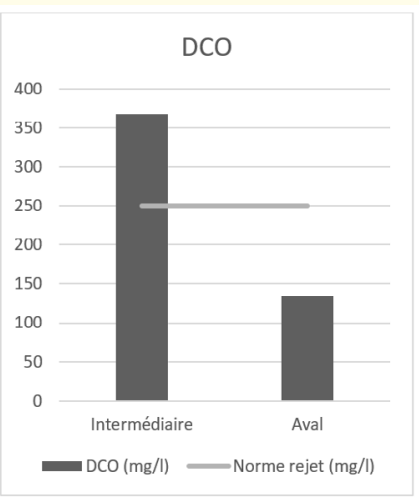

Figure 6: Chemical oxygen demand.

Similarly, suspended solids have values higher than the standard, i.e., $23 \mathrm{mg} / \mathrm{l}$ for the intermediate point and $30 \mathrm{mg} / \mathrm{l}$ for the downstream point compared to the standard (20 mg/l).

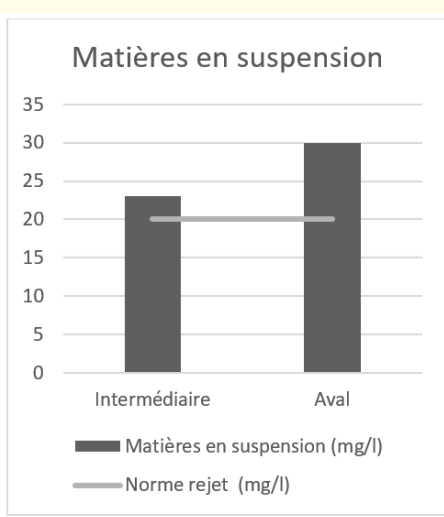

Figure 7: Suspended solids. 
The other parameters of the intermediate and downstream points (Temperature $\left(\mathrm{T}^{\circ}\right)$ 24.7, 24.4; Conductivity(cnd) 881, 1438; Phosphorus(P) 0.81, 0.32; Total nitrogen (NT) 0.306, 0.189; Dissolved Total Solids (TDS) 431, 716; five-day biological chemical demand (BOD5) 22, 12; downstream chemical oxygen demand (COD) 135; chloride (CL) 0.12, 0.05; The Hydrogen Potential (Ph) 7.8, 7.1) comply with the standard $\left(15<\mathrm{T}^{\circ}<30\right.$, Cnd $20 \mathrm{dS} / \mathrm{m}, \mathrm{P} 2 \mathrm{mg} / \mathrm{l}$, NT $1 \mathrm{mg} / \mathrm{l}$, TDS $1200 \mathrm{mg} / \mathrm{l}$, BOD5 $50 \mathrm{mg} / \mathrm{l}$, COD $250 \mathrm{mg} / \mathrm{l}$, CL 50 $\mathrm{mg} / \mathrm{l}, 6<\mathrm{Ph}<9$ ). The slaughter rate of all physical and chemical parameters was in line with MINEPDED release standards. And the COD/BOD5 ratio is 16.72 for the intermediate point and 11.25 for the downstream point. These two values being greater than 4 , tell us that the effluent is difficult to biodegrade and therefore it is necessary to consider a physico-chemical treatment.

\section{Discussion}

The work presented focused on the evaluation of the effluent management of the gynecological obstetric and pediatric hospital of Douala. It is mainly focused on the management of hospital effluents which aims to avoid environmental and health impacts. It concerns the identification of effluent sources, the existing management of effluents and the analysis of the characteristic parameters of these effluents. The work presents four main results.

In the first place, we observed that the pollutants are essentially limited to patients' fluids (blood, excreta, sputum, serums, gastric fluids, amniotic fluids, puncture fluids, tracheo-bronchitis aspiration...), medical products (acetic acids, lactic acids, citric acids, hydrochloric acids, sulfuric acids), bases (soda...), various reagents, solvents, contrasse liquids, formalin, dye, ethyl alcohol, diluents, dialysis baths, iodine-based solution....), and cleaning products (disinfectant, decontaminating, sterilizing). These results are like those obtained in LYON by EVENS Emmanuel on assessment of health and Eco toxicological risks related to hospital effluents [5]. We can say that these two results are similar because of the uniformity of the activities of health facilities.

Secondly, the one on the determination of the mode of effluent management. The results obtained here present: first, the compliance of the different stages of wastewater treatment. It appears that all the treatment steps are at the origin of the poor management of HGOPED effluents with a rate of $33.33 \%$ for pre-treatment, $50 \%$ of primary treatment, $0 \%$ of secondary treatment and tertiary treatment. In a second step the analysis of the causes of non-compliance. The main causes of non-compliance related to the misma- nagement of HGOPED effluents are: 33.33\% methods (sandblasting, deoiling, coagulation/flocculation and biological treatment) followed by $33.33 \%$ of equipment (maintenance equipment and chemicals) and financial resources at $16 \%$.

Thirdly, our results focused on the impact analysis, which first informs us about the sensitivity of the receiving environment. In addition, it gave us the following information: $54.2 \%$ of households mainly use boreholes and wells; $38.6 \%$ prefer drilling while $6.3 \%$ prefer wells only. Most of the population went to the hospital only in case of emergency, they most often complained of malaria at $37.6 \%$; typhoid at $24.8 \% ; 12.8 \%$ of amoeba. The presence of scabies is observed to the tune of $10.1 \%$. These results are like those obtained in Bafoussam-Cameroon by Reunoudji (2021) on: vulnerability to pollution of water resources and socio-economic and health impacts. The causes of such consequences come from the lack of drinking water [24-26].

Then the result of laboratory analyses showed that only the MES (intermediate $23 \mathrm{mg} / \mathrm{l}$, downstream $30 \mathrm{mg} / \mathrm{l}$ ) and intermediate COD (368 mg/l) are higher than the MINEPDED standard of respectively $20 \mathrm{mg} / \mathrm{l}, 250 \mathrm{mg} / \mathrm{l}$. All other parameters of the intermediate and downstream points due to the excessive presence of chemicals in the water. $\left(\mathrm{T}^{\circ} 24.7,24.4\right.$; Cnd 881, 1438; P 0.81, 0.32; NT 0.306, 0.189; TDS 431, 716; BOD5 22, 12; Downstream COD 135; CL $0.12,0.05 ; \mathrm{pH} 7.8,7.1$ ) comply with the standard (15 $<\mathrm{T}^{\circ}<30$, Cnd 20 dS/m, P 2 mg/l, NT 1mg/l, TDS 1200 mg/l, BOD5 $50 \mathrm{mg} / \mathrm{l}$, COD $250 \mathrm{mg} / \mathrm{l}, \mathrm{CL} 50 \mathrm{mg} / \mathrm{l}, 6<\mathrm{Ph}<9$ ). These results with regard only to the MES of the two points (intermediate and downstream) and the intermediate COD are like those obtained on the one hand on the evaluation of the effluent management of the University Hospital of Yaoundé [13]. On the other hand, on the evaluation of rainwater management in the agri-food industries: case of the Breweries of Cameroon, factory of the Central Region $[15,16,19]$. Finally, the result of the initial environmental analysis revealed that the significant environmental aspects are activities carried out in the service of anatomy-pathology.

\section{Conclusion}

Ultimately, the present study focused on the evaluation of the effluent management of the Gyneco Obstetric and Pediatric Hospital of Douala. It has focused primarily on mitigating environmental and health risks and impacts. For this, we first made a General Introduction, followed by a review of the literature, then the presentation of the study framework and the methodological approach. 
Our work ended with the rendering (results) of the application of the methods and tools used, the proposal of the actions to be implemented for the improvement of the effluent management system. The results on the management of HGOPED effluents allowed us to highlight the non-compliance of the wastewater treatment steps and the important causes (methods at $33.33 \%$, material at $33.33 \%$ and financial means at $16 \%$ ). The result of the sensitivity of the receiving environment showed us that the most recurrent waterborne diseases are malaria at $37.6 \%$; typhoid at $24.8 \%$; $12.8 \%$ of amoebae and scabies. Residents also complain of foul odors.

In view of the results obtained, it is therefore necessary to review the effluent management strategy of the gynecology and pediatric hospital of Douala. Ensuring sustainable development therefore means ensuring the economic, social and environmental preservation of health facilities.

\section{Conflicts of Interest}

The authors declare no.

\section{Bibliography}

1 A Serander. “Wastewater". Wiki Loves Africa 125 (2015).

2 AS Patrick. "Environmental Protection” (2018).

3 Georepere E. "Pollution industrielle". Medias files Yaounde (2012).

4 PACA. www.edx.org. (2017).

5 YP Evems. "Ecotoxicological Risks of Hospital Effluents" (2014).

6 S Sedrati. “Dechets hopitaliers/orignes et typologies" (2017).

7 AB Developpement. "Environmental pollution". BTC, Belgium (2019).

$8 \quad$ MY Sidibe. "Bibliosante.ml handle" (2011).

9 C Judicaël Nounagnon Todedji. "Physico-chemical and toxicological characterization of effluents from hospital and university centers of the Department of the Littoral of Benin". 3.114 (2020): 1119.

10 M Rodrique. "Management of road safety in the city of Douala". Douala (2020).

11 AS Patrick. "Debit volumetrique des effluents hospitaliers" (2018).
12 "National liquid sanitation strategy in cameroon". Yaounde (2011).

13 MM Séverin. "Evaluation de la gestion des dechets" (2012).

14 A Reounodji. "Evaluation of wastewater management of the etoudi slaughterhouse" (2016).

15 KKN Ernestine. "Evaluation of stormwater management in the agri-food industries” (2018).

16 L Kegne. "Etude du schema directeur d'assainissement de la ville de douala". Douala (2005).

17 Said "Technical and environmental risk management/dakar" (2004): 3-9.

18 A Serander. "Wastewater". Wiki Loves Africa 1.125 (2015): 2-7.

19 W Eldy. "Health care institution" 1.116 (2021): 5.

20 S Coppe. "General assessment and definition of environmental terms" (2021).

21 Marco. "Dictionnaire larousse francais" 4 (2021): 12.

22 AS Patrick. "SABC wastewater treatment" (2019).

23 F Lomber. "Studies of toxic substances of hospital effluents" (2013).

24 S Arno. "Analysis of the environmental impacts of the construction project of the $5^{\text {th }}$ jewel hotel in benin" (2016).

25 JPB Ondoua. “Cameroonian health system” (2012).

26 A Herve. "Management of hospitals and health institutions in cameroon". Forhom institute (2020).

\section{Assets from publication with us}

- Prompt Acknowledgement after receiving the article

- Thorough Double blinded peer review

- Rapid Publication

- Issue of Publication Certificate

- High visibility of your Published work

Website: www.actascientific.com/

Submit Article: www.actascientific.com/submission.php Email us: editor@actascientific.com

Contact us: +919182824667 